\title{
Endkappen für Schanz-Schrauben und Steinmann-Nägel am Fixateur externe
}

Dankward Höntzsch

Man sieht immer wieder verschiedene Schutzkappen für überstehende Schanz-Schrauben oder Steinmann-Nägel.

Es gibt hässliche, unhygienische (!) und oft schmutzig aussehende Konstruktionen.

Es werden Pflaster, Korken oder Drainageschläuche (viel zu teuer für diesen Zweck) usw. verwendet.

Eine elegante Lösung für die am häufigsten verwendete 5-mm-Schanz-Schrauben sind die kleinen „Einerle“-Legosteine ( $\bullet$ Abb. $\mathbf{1})$. Mit etwas Phantasie kann man die schönsten Steine verwenden ( $\bullet$ Abb. 2 ).

Der Autor verwendet gern die Köpfe von den Lego-Figuren ( $\bullet$ Abb. 3). In Lego-Läden (Berlin, New York...) kann man diese inzwischen 100-g-weise aus einer Kiste kaufen.

\section{Merke}

Bitte senden Sie Ihre Tipps und Tricks ein, damit dies ein lebendiger Austausch wird und wir voneinander lernen können. Bitte an: op-journal@thieme.de oder Georg Thieme Verlag KG, OP-Journal, z. Hd. Frau Stickel, Rüdigerstraße 14, 70469 Stuttgart.

Korrespondenzadresse

\section{Prof. Dr. Dankward Höntzsch}

Tübingen

hoentzsch@t-online.de

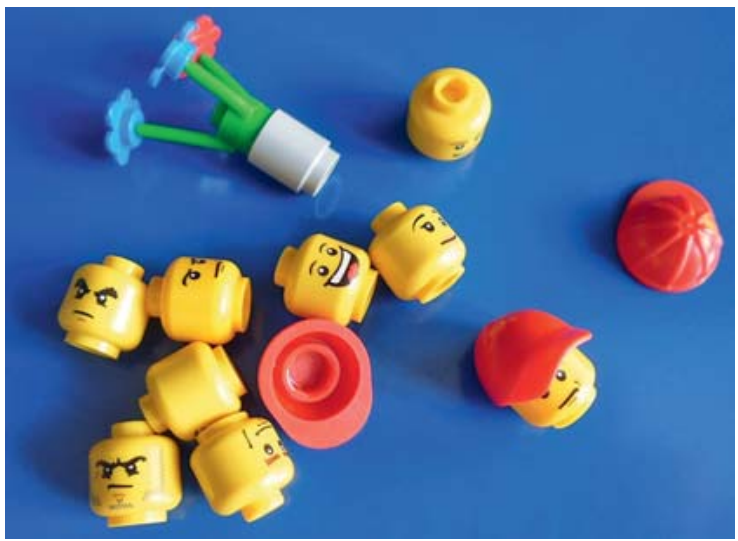

- Abb. 2 Köpfe oder alle anderen „Einerle“ eignen sich.

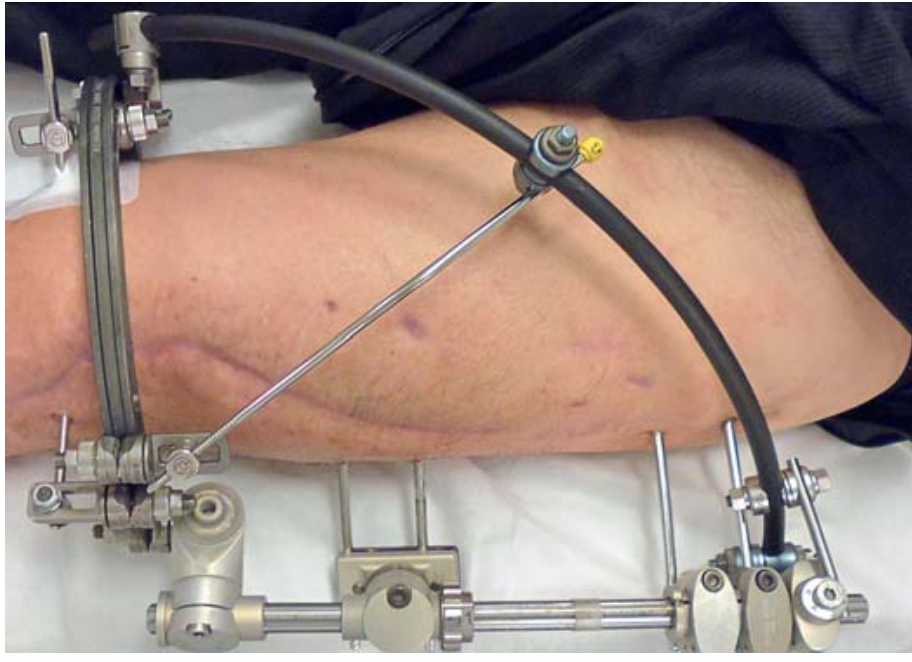

- Abb. 1 Ein Beispiel aus einer tatsächlichen Behandlung.

\section{Bibliografie}

DOI https://doi.org/10.1055/s-0043-108808

OP-JOURNAL 2018; 34: 69 @ Georg Thieme Verlag KG Stuttgart · New York ISSN 0178-1715

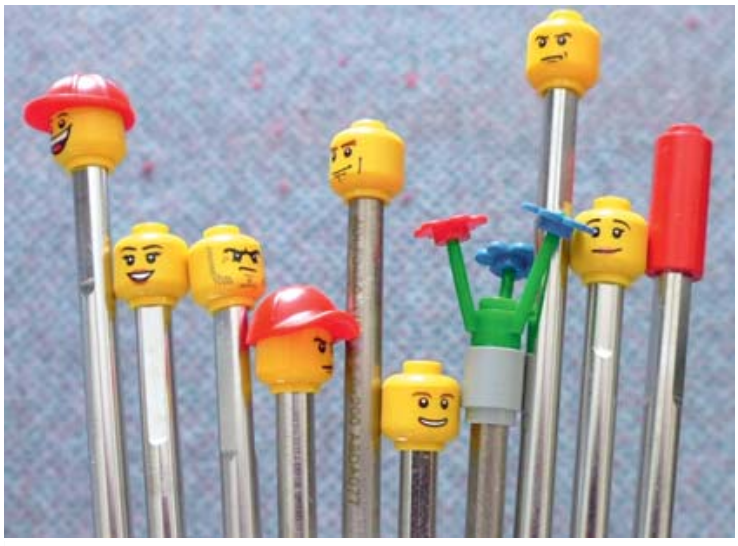

- Abb. 3 Parade von aufgesteckten Endkappen mit lachenden oder grimmigen Köpfen, Blumen oder auch einfachen Steinen. 